\title{
Campanha de vacinação na Pandemia de SarsCov2: Relato de experiência
}

RESUMO | Objetivo: Evidenciar a relevância da participação de acadêmicos de enfermagem nas campanhas de imunização em meio à pandemia de SarsCov2. Método: Trata-se de um relato de experiência, estudo descritivo da atuação dos acadêmicos de enfermagem no período de maio, junho e julho de 2020, em pontos estratégicos de uma cidade do Norte de Minas Gerais nas campanhas de imunização contra influenza, tríplice viral e dupla viral. Resultado: Atuar na campanha de vacinação em uma pandemia possibilitou o entendimento de condições e barreiras a serem enfrentadas. Conclusão: A paramentação adequada possibilitou que o trabalho acontecesse de forma segura e contínua como previsto anualmente, lembrando que a rubéola, sarampo, caxumba e influenza ainda continuam presentes mesmo em momento de pandemia de SarsCov2.

Palavras-chaves: Vacinação em massa; Pandemias; Betacoronavirus; Atenção primária à saúde.

ABSTRACT | Objective: To highlight the relevance of the participation of nursing students in immunization campaigns in the midst of the SarsCov2 pandemic. Method: This is an experience report, a descriptive study of the performance of nursing students in the period of May, June and July 2020, in strategic points of a city in the North of Minas Gerais in the campaigns of immunization against influenza, viral triple and viral duo. Result: Acting in the vaccination campaign in a pandemic enabled the understanding of conditions and barriers to be faced. Conclusion: Adequate attire made it possible for the work to take place safely and continuously as planned annually, remembering that rubella, measles, mumps and influenza are still present even at the time of the SarsCov2 pandemic.

Keywords: Mass vaccination; Pandemics; Betacoronavirus; Primary health care.

RESUMEN | Objetivo: Resaltar la relevancia de la participación de estudiantes de enfermería en campañas de inmunización en medio de la pandemia SarsCov2. Método: Se trata de un relato de experiencia, un estudio descriptivo del desempeño de estudiantes de enfermería en el período de mayo, junio y julio de 2020, en puntos estratégicos de una ciudad del norte de Minas Gerais en las campañas de inmunización contra influenza, triple viral. y dúo viral. Resultado: Actuar en la campaña de vacunación en caso de pandemia permitió comprender las condiciones y las barreras a enfrentar. Conclusión: La vestimenta adecuada hizo posible que el trabajo se realizara de manera segura y continua según lo planeado anualmente, recordando que la rubéola, el sarampión, las paperas y la influenza todavía están presentes incluso en el momento de la pandemia SarsCov2.

Palabras claves: Vacunación masiva; Pandemias; Betacoronavirus; Primeros auxilios.

\section{Joyce Lemos de Souza Botelho}

Discente em Enfermagem. Faculdades Santo Agostinho - Montes Claros - MG.

ORCID: 0000-0002-2284-9844

\section{Marta Duque de Oliveira}

Discente em Enfermagem. Faculdade Santo Agostinho - Montes Claros - MG.

ORCID: 0000-0002-6567-890X

\section{Nathan Alves de Souza}

Discente em Enfermagem. Faculdades Santo Agostinho - Montes Claros - MG. ORCID: 0000-0003-2771-2924

\section{Ingred Gimenes Cassimiro de Freitas}

Supervisora de Estágio do curso de Enfermagem. Faculdades Santo Agostinho Montes Claros - MG.Enfermeira, Mestranda em Cuidado Primário.

ORCID: 0000-0001-8325-0985

Recebido em: 12/08/2020

Aprovado em: 06/11/2020

\section{Rosana Franciele Botelho Ruas}

Docente do Curso de Enfermagem. Faculdades Santo Agostinho - Montes Claros MG. Enfermeira, Mestre em enfermagem EE/UFMG e Doutoranda em Ciências da Saúde - PPGCS/Unimontes.

ORCID: 0000-0002-6649-3966

\section{Ana Izabel de Oliveira Neta}

Enfermeira. Graduação em Enfermagem pela Universidade do Estado de Minas Gerais (UEMG) (1998-2002). Especialização em Saúde Coletiva com Ênfase em Saúde da Família pelas Faculdades Unidas do Norte de Minas (FUNORTE) (2004-2005). Especialização em Gestão Microrregional em saúde pela UEMG (2010-2012). Atualmente é professora titular de Ensino Superior nas Faculdades Santo Agostinho de Montes Claros (FASA-Moc). Preceptora de ensino clínico (estágio) do Departamento de Enfermagem da FASA-Moc. Consultora em Saúde e tutora à distância do Curso de Especialização em Estratégia Saúde da Família - Mais Médicos do Brasil/UFMG. ORCID: 0000-0003-3777-1290
INTRODUÇÃO

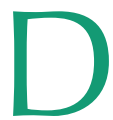
e acordo com MARGOT, 2019 a imunização atua como um mecanismo que ajuda o corpo a se defender de determinadas doenças causadas tanto por vírus quanto por bactérias. O Brasil obteve sucesso na erradicação de algumas doenças como sarampo, rubéola, coqueluche e poliomielite a partir do programa de imunização ${ }^{2}$, que atualmente é trabaIhado através do calendário nacional de imunização, a fim de otimizar a quantidade de pessoas vacinadas de forma a ampliar faixas etárias e grupos considerados de risco ${ }^{3}$.

Em 2019 foi detectado um novo Corona Vírus, da família do SarsCov2 ${ }^{4}$, que possui como principal causa de mortalidade a síndrome da angústia respiratória aguda (SDRA) ${ }^{8}$, podendo apresentar sintomatologia gripal como um leve resfria- 
do sendo desenvolvida em média de 5 a 6 dias após infecção ${ }^{9}$.

A inesperada pandemia causou mudanças radicais nos serviços de saúde, o "lockdown" e "isolamento social" a fim de mitigar transmissão, fez com que a população extinguisse a procura das salas de vacina ${ }^{6}$. No momento atual ainda não foi desenvolvida uma vacina eficaz no desempenho da imunidade adaptativa e/ou tratamento da enfermidade do SarsCov2, existe a comprovação de que o sistema imune está diretamente relacionado com agravos em quadros clínicos desta doença ${ }^{7}$. De acordo com a Sociedade Brasileira de Imunização (Sbim) 2020, tal situação pode acarretar ao retrocesso e aumento de casos de doenças imunopreviníveis e maiores índices de óbitos, além dos referentes e positivados pelo SarsCov2.

A ideia da importância da vacinação na pandemia emergiu a partir da percepção do distanciamento da população das salas de vacinas, tendo como objetivo do estudo evidenciar a relevância da participação dos acadêmicos de enfermagem em vários dias de campanha de imunização em parceria com a secretaria de saúde do município de uma cidade do norte de Minas Gerais em meio à pandemia de SarsCov2.

\section{MÉTODO}

O estudo em questão trata-se de relato de experiência, acontecido o período de maio, junho e julho de 2020, tendo limite de três meses para a imunização dos grupos alvos, sendo esses adultos entre 20 a 49 anos. vivenciado por cerca de 30 acadêmicos de enfermagem, de uma faculdade em Montes Claros., em diversos pontos estratégicos de uma cidade do norte de Minas Gerais, atuando nas campanhas de imunização contra influenza, tríplice viral (sarampo, caxumba e rubéola) e dupla viral (sarampo e rubéola). Foi utilizado como critério de exclusão idosos, crianças e gestantes. Pode-se trabalhar a análise a partir de tabelas que foram preenchidas no decorrer da ação e para cada administração de dose. Foi supervisionado de forma criteriosa pela enfermeira responsável desde a coleta de informações do lote até a aplicação da vacina.

\section{RESULTADOS}

A experiência vivenciada foi de extrema valia para os acadêmicos, possibilitou novos aprendizados acerca da imunização e sua importância em meio a acontecimentos esporádicos como uma pandemia. No momento da campanha foi necessário o uso dos conhecimentos de prevenção ao SarsCov2, solicitado que cada um respeitasse a distância preconizada na fila de espera, e como uma das estratégias para reduzir a aglomeração, foi realizado também um "Drive-trhu". Durante a coleta de dados, foi analisado faixa etária, histórico vacinal e de alergias a doses anteriores para segurança na administração da vacina, tendo como contra indicações: febre, vacinado contra febre amarela a menos de 15 dias, alergia a leite e ovo, histórico de reação anafilática, imunodepressão de qualquer natureza e estar gestante. Ainda no preenchimento dos dados pôde-se estabelecer uma oportunidade para analisar sintomatologia apresentada naquele momento e analisar o cartão de vacinação a fim de orientar sobre atualização do mesmo caso haja necessidade na unidade básica de saúde. Aonde acontecia a campanha, eram feitas as diluições conforme orientação do fabricante e necessidade de utilização, as doses eram armazenadas em temperatura entre $2^{\circ} \mathrm{C}$ e $8^{\circ} \mathrm{C}$ em caixa térmica portátil, sempre inspecionando a temperatura. No decorrer da coleta de dados e da administração das vacinas os acadêmicos faziam o uso adequado de seus equipamentos de proteção individual (máscara PFF2, óculos, luvas e jaleco), executou-se a higienização com algodão seco na região do deltóide iniciando a administração com o movimento de pinça e inserção da agulha em $90^{\circ}$ graus em 
via subcutânea sem realizar aspiração de êmbolo. Após vacinação sanava-se as dúvidas relacionadas a dor e desconforto gerado pela vacina, questionamentos quanto os sinais e sintomas relacionados ao COVID19.

\section{CONCLUSÃO}

Atuar nas campanhas de vacinação em meio uma pandemia foi um acontecimento que agregou bastante aprendizado para os acadêmicos, possibilitando aprimorar sobre as condições e barreiras que devem ser enfrentadas para obten- ...reduzindo assim aglomerações de casos suspeitos em unidades de urgência

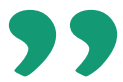

Quadro 1: principais problemas identificados e intervenções para maior alcance do público alvo e qualidade na imunização.

\begin{tabular}{|l|l|}
\hline Problemas & Intervenções \\
\hline Alta transmissibilidade do SarsCov2 & $\begin{array}{l}\text { Uso correto de EPls } \\
\text { Troca de luva a cada procedimento }\end{array}$ \\
\hline Distanciamento social & $\begin{array}{l}\text { Distância preconizada nas filas } \\
\text { Sistema "drive-trhu" }\end{array}$ \\
\hline $\begin{array}{l}\text { Não recomendado aglomeração em locais } \\
\text { fechados }\end{array}$ & Pontos estratégicos ao ar livre \\
\hline Manter temperatura ideal das vacinas & $\begin{array}{l}\text { Feito mapa de controle de temperatura } \\
\text { Uso de caixa reserva }\end{array}$ \\
\hline Logísticas com ponto estratégicos & $\begin{array}{l}\text { Parcerias que disponibilizaram locais } \\
\text { estratégicos }\end{array}$ \\
\hline Fonte própria. Minas Gerais - Brasil 2020. &
\end{tabular}

ção dos índices preconizados de imunização que o município deve alcançar durante campanha em meio à pandemia. Mostrar para a população que a equipe de saúde está preparada e paramentada para continuar seu trabalho rotineiro é imprescindível. Relembrar a população que o cuidado para uma doença não anula o cuidado para as outras, que a rubéola, sarampo, caxumba e influenza ainda continuam presentes mesmo em momento de pandemia de COVID19, e que se faz necessário reforçar as doses das vacinas para determinada faixa etária, a fim de reduzir as chances de desenvolver mais comorbidades nos pacientes, inclusive nos adultos de 20 a 49 anos, que por condições trabalhistas se expõe mais ao SarsCov2. Ressalta-se a importância da imunização contra influenza por apresentar sintomatologia semelhante à da COVID19, reduzindo assim aglomerações de casos suspeitos em unidades de urgência. A experiência agregou ainda, orientação para a população e aprendizado aos acadêmicos relacionado a imunização, normas de biossegurança, estratégias de busca ativa, prática na administração subcutânea, garantindo uma experiência profissional única, em um momento tão peculiar, contribuindo para a saúde da população.

\section{Referências}

1. Margot L. Savoy, Lewis Katz. Considerações gerais sobre a imunização. Manual MSD versão saúde da família. Kenilworth, NJ, EUA. 2019, última alteração Agosto de 2019. Disponível em <https://www.msdmanuals.com/ pt/casa/infec\%C3\%A7\%C3\%B5es/imuniza $\%$ C3\%A7\%C3\%A3o/considera $\%$ C3\%A7\%C3\%B5es-gerais-sobre-a-imuniza $\% \mathrm{C} 3 \% \mathrm{~A} 7 \% \mathrm{C} 3 \% \mathrm{~A} 30>$. Acesso em 06 de agosto de 2020.

2. Brasil. Ministério da saúde. Vacinação: quais são as vacinas, para que servem por que vacinar, mitos. Brasília DF, 2020. Disponível em: <https://www.saude. gov.br/saude-de-a-z/vacinacao>. Acesso em 07 de agosto de 2020.

3. Brasil. Secretário de estado de saúde. Vacinação. Disponível em <https:// www.saude.mg.gov.br/vacinacao >. Acesso em 07 de agosto de 2020.

4. Lana, Raquel Martins et al. Emergência do novo coronavírus (SARSCoV-2) e o papel de uma vigilância nacional em saúde oportuna e efetiva. Cadernos de Saúde Pública [online]. v. 36, n. 3.. Disponível em: <https://doi. org/10.1590/0102-311X00019620>. Acesso em 05 Agosto 2020

5. Brasil. Pandemia da COVID19. 0 que muda na rotina das Imunizaç̃es. 1 ed. [online] junho de 2020. Disponível em <https://sbim.org.br/images/files/ cartilha-campanha-sbim-sbp-unicef-200611b-web.pdf>. Acesso em 06 de agosto de 2020.
6. Dias, Josy Lira. Nascimento, Maria Izabel Nogueira. A campanha da influenza 2020 em meio a pandemia do coronavírus no estado do amazonas: Um relato de experiência. Rev. eletrônica acervo saúde [online]. Vol. Esp. n. 46. Junho de 2020. Disponível em <https://doi.org/10.25248/reas.e4053.2020>. Acesso em 06 de agosto de 2020.

7. Silva de Sordi LH, Sales Oliveira Magalhães I, Abreu Casselhas D, Chaves Andrade M. 0 Papel da Imunidade Inata na COVID-19. Rev Cienc Saude [Internet]. $2^{\circ}$ de julho de 2020 [citado $12^{\circ}$ de agosto de 2020];10(3):5-. Disponível em: <http://186.225.220.186:7474/ojs/index.php/rcsfmit_zero/article/ view/997> Acesso em 12de agosto de 2020.

8. Mehta, Puja et al. "COVID-19: considere síndromes de tempestade de citocinas e imunossupressão." [Online] Londres, Inglaterra vol. 395,10229 (2020): 1033-1034. Disponível em: <https://doi.org/10.1016/S0140-6736(20)30628$0>$ Acesso em 12 de agosto de 2020.

9. Lima, Claudio Márcio Amaral de Oliveira. Informações sobre o novo coronavírus (COVID-19). Radiol Bras [Internet]. Abril de 2020 [citado em 12 de agosto de 2020]; 53 (2):V-VI. Disponível em: < http://dx.doi.org/10.1590/01003984.2020.53.2e1>. Acesso em 12 de agosto de 2020. 